\title{
Association between physiological responses after exercise at low altitude and acute mountain sickness upon ascent is sex-dependent
}

Yang Shen ${ }^{1,2+}$, Yuan-Qi Yang ${ }^{1,2+}$, Chuan Liu ${ }^{1,2}$, Jie Yang ${ }^{1,2}$, Ji-Hang Zhang ${ }^{1,2}$, Jun Jin ${ }^{1,2}$, Hu Tan ${ }^{1,2}$, Fang-Zheng-Yuan Yuan ${ }^{1,2}$, Jing-Bin Ke ${ }^{1,2}$, Chun-Yan He ${ }^{1,2}$, Lai-Ping Zhang ${ }^{1,2}$, Chen Zhang ${ }^{1,2}$, Jie Yu $\mathrm{u}^{1,2}$ and Lan Huang ${ }^{1,2^{*}}$ (D)

\section{Abstract}

Background: Acute mountain sickness (AMS) is the mildest form of acute altitude illnesses, and consists of nonspecific symptoms when unacclimatized persons ascend to elevation of $\geq 2500 \mathrm{~m}$. Risk factors of AMS include: the altitude, individual susceptibility, ascending rate and degree of pre-acclimatization. In the current study, we examined whether physiological response at low altitude could predict the development of AMS.

Methods: A total of 111 healthy adult healthy volunteers participated in this trial; and 99 (67 men and 32 women) completed the entire study protocol. Subjects were asked to complete a 9-min exercise program using a mechanically braked bicycle ergometer at low altitude $(500 \mathrm{~m})$. Heart rate, blood pressure $(\mathrm{BP})$ and pulse oxygen saturation $\left(\mathrm{SpO}_{2}\right)$ were recorded prior to and during the last minute of exercise. The ascent from $500 \mathrm{~m}$ to $4100 \mathrm{~m}$ was completed in 2 days. AMS was defined as $\geq 3$ points in a 4-item Lake Louise Score, with at least one point from headache wat $6-8 \mathrm{~h}$ after the ascent.

Results: Among the 99 assessable subjects, 47 (23 men and 24 women) developed AMS at $4100 \mathrm{~m}$. In comparison to the subjects without AMS, those who developed AMS had lower proportion of men (48.9\% vs. $84.6 \%, P<0.001)$, height $(168.4 \pm 5.9$ vs. $171.3 \pm 6.1 \mathrm{~cm}, P=0.019)$, weight ( $62.0 \pm 10.0 \mathrm{vs} .66 .7 \pm 8.6 \mathrm{~kg}, P=0.014)$ and proportion of smokers (23.4\% vs. $51.9 \%, P=0.004$ ). Multivariate regression analysis revealed the following independent risks for AMS: female sex (odds ratio $(O R)=6.32, P<0.001), \mathrm{SpO}_{2}$ change upon exercise at low altitude $(O R=0.63, P=0.002$ ) and systolic $\mathrm{BP}$ change after the ascent $(O R=0.96, P=0.029)$. Women had larger reduction in $\mathrm{SpO}_{2}$ after the ascent, higher AMS percentage and absolute AMS score. Larger reduction of $\mathrm{SpO}_{2}$ after exercise was associated with both AMS incidence $(P=0.001)$ and AMS score $(P<0.001)$ in men but not in women.

Conclusions: Larger $\mathrm{SpO}_{2}$ reduction after exercise at low altitude was an independent risk for AMS upon ascent. Such an association was more robust in men than in women.

(Continued on next page)

\footnotetext{
* Correspondence: huanglan260@126.com

†Yang Shen and Yuan-Qi Yang contributed equally to this work.

'Institute of Cardiovascular Diseases of PLA, the Second Affiliated Hospital,

Army Medical University, Chongqing 400037, China

2Department of Cardiology, the Second Affiliated Hospital, Army Medical

University, Chongqing 400037, China
}

C C The Author(s). 2020 Open Access This article is licensed under a Creative Commons Attribution 4.0 International License, which permits use, sharing, adaptation, distribution and reproduction in any medium or format, as long as you give appropriate credit to the original author(s) and the source, provide a link to the Creative Commons licence, and indicate if changes were made. The images or other third party material in this article are included in the article's Creative Commons licence, unless indicated otherwise in a credit line to the material. If material is not included in the article's Creative Commons licence and your intended use is not permitted by statutory regulation or exceeds the permitted use, you will need to obtain permission directly from the copyright holder. To view a copy of this licence, visit http://creativecommons.org/licenses/by/4.0/ The Creative Commons Public Domain Dedication waiver (http://creativecommons.org/publicdomain/zero/1.0/) applies to the data made available in this article, unless otherwise stated in a credit line to the data. 
(Continued from previous page)

Trial registration: Chinese Clinical Trial Registration, ChiCTR1900025728. Registered 6 September 2019.

Keywords: High altitude, Exercise testing, Sex differences, Acute mountain sickness, Individual susceptibility

\section{Background}

Acute mountain sickness (AMS) is the mildest form of acute altitude illnesses that typically occur in unacclimatized persons upon ascent to elevation at $\geq 2500 \mathrm{~m}$. AMS consists of a series of non-specific symptoms, including headache, dizziness, lightheadedness, gastrointestinal symptoms and fatigue $[1,2]$. Over $50 \%$ of individuals develop AMS when ascending to elevation at $\geq 6000 \mathrm{~m}$ [3]. In most cases, AMS spontaneously resolve after a few days at high altitude, but may progress to fatal high-altitude cerebral edema (HACE) [4].

Known risk factors for AMS include ascending speed, arrival elevation and individual susceptibility [3]. People who live at sea level for generations and those with a history of AMS or migraine are also reported to be at high risk for developing AMS [5]. Age, sex, smoking status and obesity have been associated with AMS in some but not all studies [5-9]. For example, younger subjects were found to be more susceptible to AMS $[5,8]$. Gonggalanzi et al. [6] also found that age below 55 years was an independent AMS risk factor, but smoking reduced the risk of AMS. In a study by Meier et al. [7], younger age (<50 years) was an AMS risk factor but smoking was not associated with AMS. Sex discrepancy, but again with controversial results. Lower susceptibility has been reported in men by some studies [10-12], whereas other studies reported either no difference or increased susceptibility in men [13-15].

Upon ascending to high altitude, a number of physiological responses are activated to adapt to decreased arterial oxygen saturation $\left(\mathrm{SaO}_{2}\right)$. Sympathetic autonomic system is activated, with resulting vasoconstriction and increased blood pressure (BP) and heart rate (HR) [16]. Previous studies suggested that $\mathrm{SpO}_{2}$ reduction and physiological response after exercise at high altitude could be useful in assessing the degree of acclimatization to high altitude [17, 18]. More specifically, $\mathrm{SpO}_{2}$ reduction after exercise prior to ascending has been shown to be a risk factor for severe high-altitude illness (HAI) that included severe AMS, HACE and high-altitude pulmonary edema [8]. However, another study indicated that association between $\mathrm{SpO}_{2}$ and AMS is not strongly altitude-independent during the first 7 days of trekking [19]. Another important caveat that adds to the complexity of the controversy is the physiological and functional differences between men and women $[20,21]$.

In the current prospective cohort study, we examined reduction of $\mathrm{SpO}_{2}$ as well as $\mathrm{HR}$ and $\mathrm{BP}$ changes upon exercise in a group of healthy volunteers prior to ascending from 500 to $4100 \mathrm{~m}$. Characteristics of those who developed AMS vs not were compared. Multivariate analysis was used to determine whether exerciseinduced responses at low altitude prior to ascent could be used to predict AMS and whether such an association is sex-dependent.

\section{Methods}

\section{Design and participants}

We performed this prospective cohort study on the Qinghai-Tibet plateau in June 2019. A total of 111 unrelated healthy Chinese Han volunteers born and permanently lived in low altitude $(\leq 500 \mathrm{~m})$ without travelling to high-altitude areas $(\geq 2500 \mathrm{~m})$ in the past 6 months were approached. Exclusion criteria included: a history of AMS, migraine, cardiopulmonary diseases, neurological diseases, psychiatric disorders that prevented the completion of data collection, cerebral vascular diseases, cancer, or liver or kidney dysfunction, long-term use of any medications. Body mass index (BMI) was calculated as body weight in $\mathrm{kg}$ divided by square height in meter.

\section{Exercise program}

The testing was conducted prior to the ascent at $500 \mathrm{~m}$. Exercise testing was conducted using a mechanically braked bicycle ergometer (Ergoline 900EL, Ergoline Company, Germany) [22]. The session consisted of a 3-min warm-up period with no resistance, a 3-min initial exercise phase at 25-W workload and a 3-min maintenance exercise phase with $50-\mathrm{W}$ workload. $\mathrm{HR}, \mathrm{BP}$ and $\mathrm{SpO}_{2}$ were recorded during the last minute of the session. $\mathrm{BP}$ and $\mathrm{HR}$ were recorded using an electronic sphygmomanometer (Omron HEM6200, Japan). $\mathrm{SpO}_{2}$ values was determined using a pulse oximeter (Nonin ONYX OR9500, USA). The average of 3 measures was used in data analysis.

\section{Assessment of AMS}

Subjects ascended from $500 \mathrm{~m}$ to $4100 \mathrm{~m}$ in 2 days. AMS was assessed using the latest Lake Louise questionnaire [1] at 6-8 h after arriving at $4100 \mathrm{~m}$. Participant completed a 4-item questionnaire with the assistance of an experienced doctor. The items included headache, dizziness or lightheadedness, gastrointestinal symptoms and fatigue. The score for each item ranged from 0 to 3: 0 for no, 1 for mild, 2 for moderate, and 3 for severe. AMS was defined as the total scores at $\geq 3$ points, with at least one point from headache. 


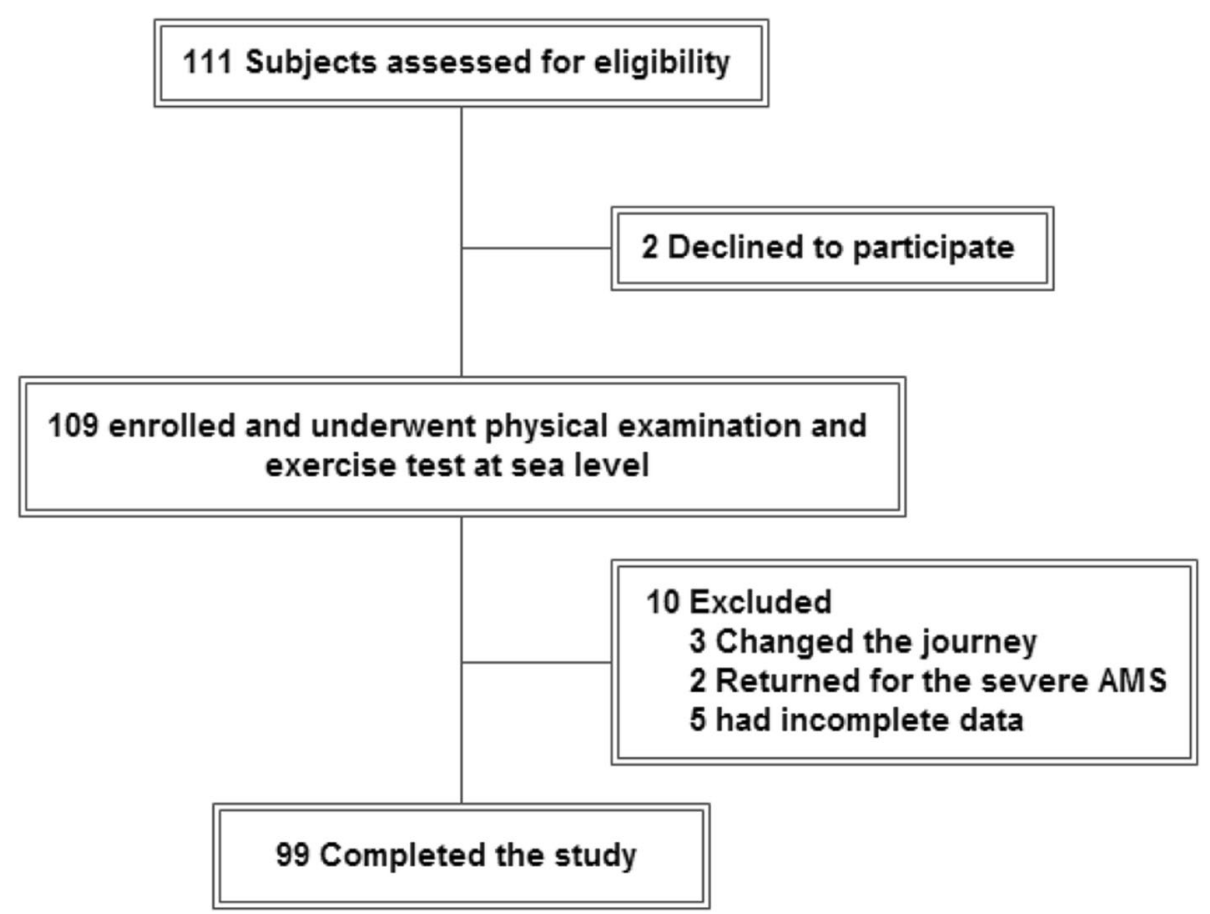

Fig. 1 The flowchart of the selection process

\section{Statistical analysis}

Statistical analyses were performed using SPSS 24.0 (Chicago, USA). Continuous variables are expressed as the mean \pm standard deviation (SD), and group comparison was conducted using Student's $t$-test or Welch's test. Categorical variables are expressed as $n$ (\%) and compared using the chi-square test or Fisher's exact test. Univariate logistic regression analysis was performed to evaluate the odds ratio $(O R)$ with a 95\% confidence interval (CI) for the factors associated with AMS. Then, multivariate logistic regression analysis was conducted of the potential risk factors $(P<0.1$ for enter, and $P<0.05$ for stay). Linear regression was applied to assess the correlation between the changes in physiological parameters after exercise and AMS score. A two-sided $P<0.05$ was considered statistically significant.

\section{Results}

\section{Subjects with vs without AMS}

A total of 111 healthy adult subjects were invited to participate: 2 refused to participate, 3 did not adhere to the pre-planned ascent plan, 2 developed severe HAI during the ascending process and were immediately transferred to low-altitude areas for emergency medical interventions, and 5 had incomplete data. Among the 99 subjects in the final data analysis, 47 developed AMS (Fig. 1). Age did not differ significantly between the subjects who developed AMS (26.0 \pm 7.7 years) vs without AMS $(27.6 \pm 8.8$ years) (Table 1$)$. The AMS group had higher proportion of women ( $51.1 \%$ vs. $15.4 \%, P<0.001)$, lower height $(168.4 \pm 5.9$ vs. $171.3 \pm 6.1 \mathrm{~cm}, P=0.019)$, weight $(62.0 \pm 10.0$ vs. $66.7 \pm 8.6 \mathrm{~kg}, P=0.014)$ and percentage of smokers $(23.4 \%$ vs. $51.9 \%, P=0.004) . \mathrm{SpO}_{2}$ at rest at low altitude was higher in the AMS group $(97.5 \% \pm 1.2 \%$ vs. $96.8 \% \pm 1.4 \%, P=0.017) . \mathrm{SpO}_{2}$ reduction at the end of the 9-min exercise session at low altitude was larger in the AMS group $(-0.6 \% \pm 1.7 \%$ vs. $0.4 \% \pm 1.7 \% ; P=$ $0.004)$. The AMS group also had lower systolic BP $(118.2 \pm 11.8$ vs. $126.0 \pm 16.3) \mathrm{mmHg}, P=0.008)$ as well as smaller change in systolic BP $(1.0 \pm 15.0$ vs. $8.7 \pm 15.0$ $\mathrm{mmHg}, P=0.013$ ) upon arrival at $4100 \mathrm{~m}$.

\section{Factors associated with AMS}

In the univariate analysis that included all subjects, female sex $(O R=5.74,95 \%$ CI 2.23-14.78, $P<0.001)$ and higher $\mathrm{SpO}_{2}$ at rest at $500 \mathrm{~m}(\mathrm{OR}=1.47,95 \% \mathrm{CI} 1.06-$ 2.03, $P=0.021)$ were associated with increased risk of AMS. Greater height $(O R=0.92,95 \%$ CI 0.86-0.99, $P=$ $0.023)$, heavier weight $(O R=0.95,95 \%$ CI $0.90-0.99, P=$ 0.016), smoking $(O R=0.28,95 \%$ CI $0.12-0.67, P=0.004)$ and greater change in SBP after arriving at $4100 \mathrm{~m}(O R=$ $0.97,95 \%$ CI $0.94-0.99, P=0.016$ ) were associated with decreased incidence of AMS. Multivariate regression that included all subjects identified the following risks for AMS: female sex $(P<0.001)$, greater $\mathrm{SpO}_{2}$ reduction after exercise at $500 \mathrm{~m}(P=0.002)$ and smaller change in SBP after arriving at $4100 \mathrm{~m}(P=0.029)$ (Table 2). 
Table 1 Baseline characteristics, exercise testing results, and measures upon arriving at $4100 \mathrm{~m}$

\begin{tabular}{|c|c|c|c|c|}
\hline Index & Total $(n=99)$ & AMS $(n=47)$ & Non-AMS $(n=52)$ & $P$-value \\
\hline \multicolumn{5}{|l|}{ Baseline characteristics } \\
\hline Age (year, $x \pm s$ ) & $26.9 \pm 8.3$ & $26.0 \pm 7.7$ & $27.6 \pm 8.8$ & 0.358 \\
\hline Men $[n(\%)]$ & $67(67.7)$ & $23(48.9)$ & $44(84.6)$ & $<0.001$ \\
\hline Women $[n(\%)]$ & $32(32.3)$ & $24(51.1)$ & $8(15.4)$ & $<0.001$ \\
\hline Height $(\mathrm{cm}, x \pm s)$ & $170.0 \pm 6.1$ & $168.4 \pm 5.9$ & $171.3 \pm 6.1$ & 0.019 \\
\hline Weight $(\mathrm{kg}, x \pm s)$ & $64.5 \pm 9.5$ & $62.0 \pm 10.0$ & $66.7 \pm 8.6$ & 0.014 \\
\hline BMI $\left(\mathrm{kg} / \mathrm{m}^{2}, x \pm s\right)$ & $22.3 \pm 2.5$ & $21.8 \pm 2.7$ & $22.7 \pm 2.2$ & 0.070 \\
\hline Smoker $[n(\%)]$ & $38(38.4)$ & $11(23.4)$ & $27(51.9)$ & 0.004 \\
\hline $\mathrm{HR}$ at rest (beats/min, $x \pm s$ ) & $73.2 \pm 11.2$ & $74.5 \pm 10.9$ & $71.9 \pm 11.5$ & 0.257 \\
\hline $\mathrm{SpO}_{2}$ at rest $(\%, x \pm s)$ & $97.1 \pm 1.3$ & $97.5 \pm 1.2$ & $96.8 \pm 1.4$ & 0.017 \\
\hline $\mathrm{SBP}$ at rest $(\mathrm{mmHg}, x \pm s)$ & $117.3 \pm 12.1$ & $117.2 \pm 12.6$ & $117.4 \pm 11.8$ & 0.937 \\
\hline $\mathrm{DBP}$ at rest $(\mathrm{mmHg}, x \pm s)$ & $73.5 \pm 11.4$ & $73.8 \pm 12.3$ & $73.4 \pm 10.6$ & 0.858 \\
\hline \multicolumn{5}{|l|}{ After exercise testing } \\
\hline $\mathrm{SpO}_{2}$ after exercise $(\%, x \pm s)$ & $97.1 \pm 1.2$ & $96.9 \pm 1.3$ & $97.2 \pm 1.1$ & 0.130 \\
\hline$\Delta \mathrm{eSpO}_{2}(\%, x \pm s)$ & $-0.1 \pm 1.8$ & $-0.6 \pm 1.7$ & $0.4 \pm 1.7$ & 0.004 \\
\hline \multicolumn{5}{|l|}{ After arriving at $4100 \mathrm{~m}$} \\
\hline $\mathrm{SBP}$ at $\mathrm{HA}(\mathrm{mmHg}, x \pm s)$ & $122.3 \pm 14.8$ & $118.2 \pm 11.8$ & $126.0 \pm 16.3$ & 0.008 \\
\hline$\Delta \mathrm{hSBP}(\mathrm{mmHg}, x \pm s)$ & $5.0 \pm 15.4$ & $1.0 \pm 15.0$ & $8.7 \pm 15.0$ & 0.013 \\
\hline
\end{tabular}

AMS Acute mountain sickness, $B M I$ Body mass index, $H R$ Heart rate, $S p O_{2}$ Pulse oxygen saturation, $S B P$ Systolic blood pressure, $D B P$ Diastolic blood pressure, $\triangle e$ Change after exercise testing (from the pre-exercise level), $\Delta h$ Change after arriving at $4100 \mathrm{~m}$ (from the $500-\mathrm{m}$ level)

Table 2 Regression analyses of the risk for AMS in the entire cohort

\begin{tabular}{|c|c|c|c|c|}
\hline \multirow[t]{2}{*}{ Variable } & \multicolumn{2}{|c|}{ Univariate analysis } & \multicolumn{2}{|c|}{ Multivariate analysis } \\
\hline & OR $(95 \% \mathrm{Cl})$ & $P$-value & OR $(95 \% \mathrm{Cl})$ & $P$-value \\
\hline Age & $0.98(0.93-1.03)$ & 0.361 & Not entered & \\
\hline Female sex & $5.74(2.23-14.78)$ & $<0.001$ & $6.32(2.25-17.74)$ & $<0.001$ \\
\hline Height & $0.92(0.86-0.99)$ & 0.023 & - & \\
\hline Weight & $0.95(0.90-0.99)$ & 0.016 & - & \\
\hline Smoking & $0.28(0.12-0.67)$ & 0.004 & - & \\
\hline HR at rest & $1.02(0.99-1.06)$ & 0.255 & Not entered & \\
\hline $\mathrm{SpO}_{2}$ at rest & $1.47(1.06-2.03)$ & 0.021 & - & \\
\hline SBP at rest & $1.00(0.97-1.03)$ & 0.936 & Not entered & \\
\hline DBP at rest & $1.00(0.97-1.04)$ & 0.856 & Not entered & \\
\hline$\Delta \mathrm{eHR}$ & $0.98(0.95-1.01)$ & 0.231 & Not entered & \\
\hline$\Delta \mathrm{eSpO}_{2}$ & $0.83(0.67-1.03)$ & 0.091 & $0.63(0.47-0.84)$ & 0.002 \\
\hline$\triangle \mathrm{eSBP}$ & $1.00(0.97-1.02)$ & 0.778 & Not entered & \\
\hline$\triangle \mathrm{eDBP}$ & $1.00(0.97-1.03)$ & 0.982 & Not entered & \\
\hline$\Delta \mathrm{hHR}$ & $1.00(0.97-1.03)$ & 0.893 & Not entered & \\
\hline$\Delta \mathrm{hSpO}_{2}$ & $0.97(0.88-1.07)$ & 0.525 & Not entered & \\
\hline$\triangle \mathrm{hSBP}$ & $0.97(0.94-0.99)$ & 0.016 & $0.96(0.93-1.00)$ & 0.029 \\
\hline$\triangle \mathrm{hDBP}$ & $0.97(0.94-1.00)$ & 0.059 & - & \\
\hline
\end{tabular}

OR Odds ratio, 95\% Cl 95\% confidence intervals, AMS Acute mountain sickness, $B M I$ Body mass index, $H R$ Heart rate, $\mathrm{SpO}_{2}$ Pulse oxygen saturation, SBP Systolic blood pressure, $D B P$ Diastolic blood pressure, $\triangle e$ Change after exercise testing, $\Delta h$ Change after arriving at $4100 \mathrm{~m}$

\section{Sex discrepancy}

Table 3 shows basic characteristics, exercise testing results and measures after arriving at $4100 \mathrm{~m}$ in men vs women. In comparison to men, the women were younger ( $23.3 \pm 3.7$ vs. $28.5 \pm 9.3$ years, $P<0.001)$, shorter $(165.0 \pm 4.1$ vs. $172.5 \pm$ $5.2 \mathrm{~cm}, P<0.001)$, and lighter $(55.4 \pm 5.3$ vs. $68.8 \pm 7.9 \mathrm{~kg}$, $P<0.001)$, had lower BMI $\left(20.5 \pm 1.9\right.$ vs. $23.1 \pm 2.2 \mathrm{~kg} / \mathrm{m}^{2}$, $P<0.001)$, smaller proportion of smokers $(3.1 \%$ vs. $55.2 \%$, $P<0.001)$, lower SBP at rest at $500 \mathrm{~m}(112.7 \pm 11.9$ vs. $119.4 \pm 11.7 \mathrm{mmHg}, P=0.011$ ), but higher $\mathrm{SpO}_{2}$ at rest at $500 \mathrm{~m}(97.6 \pm 1.2 \%$ vs. $96.9 \pm 1.4 \%, P=0.016)$. After exercise testing, women had lower SBP $(118.1 \pm 11.7$ vs. $126.5 \pm 11.4$ $\mathrm{mmHg}, P=0.001)$ and higher $\mathrm{SpO}_{2}(97.6 \pm 0.8 \%$ vs. $96.8 \pm$ $1.3 \%, P<0.001)$. Upon arriving at $4100 \mathrm{~m}$, women had lower SBP $(113.9 \pm 11.5$ vs. $126.3 \pm 14.6 \mathrm{mmHg}, P<0.001)$, lower $\mathrm{SpO}_{2}(85.9 \pm 4.3 \%$ vs. $87.8 \pm 3.5 \%, P=0.034)$ and greater $\mathrm{SpO}_{2}$ reduction $(-11.6 \pm 4.2 \%$ vs. $-9.1 \pm 3.9 \%, P=0.005)$.

\section{The rate of AMS and relevant symptoms in men vs women}

In comparison to men, women had higher rate of AMS (75.0\% vs. $34.3 \%, P<0.001)$, average AMS score $(3.4 \pm$ 2.0 vs. $1.9 \pm 1.4, P<0.001)$. The rate of dizziness, gastrointestinal symptoms and fatigue were also higher in women than in men $(71.9 \%$ vs. $43.3 \%, P=0.010,37.5 \%$ vs. $11.9 \%, P=0.006$; $90.6 \%$ vs. $58.2 \%, P=0.001$; respectively, Table 4 ). 
Table 3 Baseline characteristics, exercise testing results and measures after arriving at $4100 \mathrm{~m}$ : men vs women

\begin{tabular}{|c|c|c|c|}
\hline Index & Women $(n=32)$ & Men $(n=67)$ & $P$-value \\
\hline \multicolumn{4}{|l|}{ Baseline characteristics } \\
\hline Age (year, $x \pm s$ ) & $23.3 \pm 3.7$ & $28.5 \pm 9.3$ & $<0.001$ \\
\hline Height $(\mathrm{cm}, x \pm s)$ & $165.0 \pm 4.1$ & $172.5 \pm 5.2$ & $<0.001$ \\
\hline Weight $(\mathrm{kg}, x \pm s)$ & $55.4 \pm 5.3$ & $68.8 \pm 7.9$ & $<0.001$ \\
\hline BMI $\left(\mathrm{kg} / \mathrm{m}^{2}, x \pm s\right)$ & $20.5 \pm 1.9$ & $23.1 \pm 2.2$ & $<0.001$ \\
\hline Smoker $[n(\%)]$ & $1(3.1)$ & $37(55.2)$ & $<0.001$ \\
\hline HR at rest (beats/min, $x \pm s$ ) & $75.3 \pm 10.3$ & $72.2 \pm 11.6$ & 0.195 \\
\hline $\mathrm{SpO}_{2}$ at rest $(\%, x \pm s)$ & $97.6 \pm 1.2$ & $96.9 \pm 1.4$ & 0.016 \\
\hline $\mathrm{SBP}$ at rest $(\mathrm{mmHg}, x \pm s)$ & $112.7 \pm 11.9$ & $119.4 \pm 11.7$ & 0.011 \\
\hline $\mathrm{DBP}$ at rest $(\mathrm{mmHg}, x \pm s)$ & $72.1 \pm 9.5$ & $74.3 \pm 12.2$ & 0.374 \\
\hline \multicolumn{4}{|l|}{ After exercise testing } \\
\hline $\mathrm{SpO}_{2}$ after exercise $(\%, x \pm s)$ & $97.6 \pm 0.8$ & $96.8 \pm 1.3$ & $<0.001$ \\
\hline SBP after exercise $(\mathrm{mmHg}, x \pm s)$ & $118.1 \pm 11.7$ & $126.5 \pm 11.4$ & 0.001 \\
\hline$\Delta \mathrm{eSpO}{ }_{2}(\%, x \pm s)$ & $0.0 \pm 1.3$ & $-0.1 \pm 1.9$ & 0.791 \\
\hline$\Delta \mathrm{eSBP}(\mathrm{mmHg}, x \pm s)$ & $5.3 \pm 17.1$ & $7.1 \pm 12.6$ & 0.575 \\
\hline \multicolumn{4}{|l|}{ Upon arriving at $4100 \mathrm{~m}$} \\
\hline $\mathrm{SpO}_{2}(\%, x \pm s)$ & $85.9 \pm 4.3$ & $87.8 \pm 3.5$ & 0.034 \\
\hline $\mathrm{SBP}(\mathrm{mmHg}, x \pm s)$ & $113.9 \pm 11.5$ & $126.3 \pm 14.6$ & $<0.001$ \\
\hline$\Delta \mathrm{hSpO}_{2}(\%, x \pm s)$ & $-11.6 \pm 4.2$ & $-9.1 \pm 3.9$ & 0.005 \\
\hline$\Delta \mathrm{hSBP}(\mathrm{mmHg}, x \pm s)$ & $1.2 \pm 14.6$ & $6.9 \pm 15.5$ & 0.080 \\
\hline
\end{tabular}

AMS Acute mountain sickness, BMI Body mass index, $\mathrm{HR}$ Heart rate, $\mathrm{SPO}_{2}$ Pulse oxygen saturation, SBP Systolic blood pressure, DBP Diastolic blood pressure, $\triangle e$ Change after exercise testing, $\Delta h$ Change after arriving at $4100 \mathrm{~m}$

\section{Factors associated with AMS in men vs women}

In the analysis that included only women, AMS was associated with $\triangle \mathrm{SpO}_{2}$ upon arriving at $4100 \mathrm{~m}$ (adjusted $\mathrm{OR}=$ $1.47,95 \%$ CI 1.01 to $2.12, P=0.042$ ), and not any other factors (Table 5). In the analysis that included only men, AMS was associated with $\Delta \mathrm{SpO}_{2}$ after exercise testing at $500 \mathrm{~m}$ (adjusted $O R=0.56,95 \% \mathrm{CI} 0.39$ to $0.79, P=0.001$ ).

\section{Association of AMS score with $\mathrm{SpO}_{2}$ reduction after exercise at $500 \mathrm{~m}$}

In the linear regression analysis, AMS score was associated with $\Delta \mathrm{SpO}_{2}$ after exercise testing at $500 \mathrm{~m}$ in men $(r=-0.408, P<0.001)$ but not in women $(r=0.264, P=$ 0.144) (Fig. 2).

\section{Discussion}

The results from the current study showed higher AMS rate in women than in men. The female sex and greater $\mathrm{SpO}_{2}$ reduction after exercise at low altitude prior to the ascent were independently associated with increased risk of AMS. Interestingly, $\mathrm{SpO}_{2}$ reduction at low altitude was associated with the risk of AMS and higher AMS score in men but not in women.

\section{Incidence of AMS}

Previous studies have estimated that $10-70 \%$ of travelers will experience various degrees of AMS when ascending to elevation of $\geq 2500 \mathrm{~m}$ [6]. At $4500-5500 \mathrm{~m}$, the incidence of AMS in unacclimatized persons has been estimated at 50-85\% [5]. In army recruits ascending from

Table $\mathbf{4}$ The rate of AMS and symptoms in men vs women

\begin{tabular}{llll}
\hline Index & Women $(\boldsymbol{n}=\mathbf{3 2})$ & Men $(\boldsymbol{n}=\mathbf{6 7})$ & $\boldsymbol{P}$-value \\
\hline AMS $[n(\%)]$ & $24(75.0)$ & $23(34.3)$ & $<0.001$ \\
AMS score $(x \pm s)$ & $3.4 \pm 2.0$ & $1.9 \pm 1.4$ & $<0.001$ \\
Headache $[n(\%)]$ & $25(78.1)$ & $42(62.7)$ & 0.169 \\
Dizziness $[n(\%)]$ & $23(71.9)$ & $29(43.3)$ & 0.010 \\
Gastrointestinal symptoms $[n(\%)]$ & $12(37.5)$ & $8(11.9)$ & 0.006 \\
Fatigue $[n(\%)]$ & $29(90.6)$ & $39(58.2)$ & 0.001 \\
\hline
\end{tabular}


Table 5 Regression analyses in men vs. women

\begin{tabular}{|c|c|c|c|c|}
\hline \multirow[t]{2}{*}{ Variable } & \multicolumn{2}{|c|}{ Unadjusted analysis } & \multicolumn{2}{|c|}{ Adjusted analysis } \\
\hline & OR $(95 \% \mathrm{Cl})$ & $P$-value & OR $(95 \% \mathrm{Cl})$ & $P$-value \\
\hline \multicolumn{5}{|l|}{ Women } \\
\hline HR at rest & $0.98(0.91-1.07)$ & 0.695 & $0.98(0.88-1.08)$ & 0.632 \\
\hline $\mathrm{SpO}_{2}$ at rest & $1.06(0.54-2.09)$ & 0.862 & $1.12(0.53-2.38)$ & 0.767 \\
\hline $\mathrm{SBP}$ at rest & $1.06(0.98-1.15)$ & 0.155 & $1.08(0.96-1.20)$ & 0.199 \\
\hline DBP at rest & $0.99(0.91-1.08)$ & 0.879 & $0.95(0.85-1.07)$ & 0.416 \\
\hline$\Delta \mathrm{eHR}$ & $1.02(0.96-1.08)$ & 0.589 & $1.01(0.94-1.09)$ & 0.726 \\
\hline$\Delta \mathrm{eSpO}{ }_{2}$ & $1.10(0.59-2.05)$ & 0.758 & $0.98(0.47-2.01)$ & 0.946 \\
\hline$\triangle \mathrm{eSBP}$ & $0.98(0.93-1.03)$ & 0.348 & $0.98(0.91-1.04)$ & 0.442 \\
\hline$\triangle \mathrm{eDBP}$ & $0.96(0.90-1.03)$ & 0.270 & $0.96(0.89-1.03)$ & 0.268 \\
\hline$\Delta \mathrm{hHR}$ & $1.00(0.95-1.06)$ & 0.959 & $1.00(0.93-1.07)$ & 0.938 \\
\hline$\Delta \mathrm{hSpO}_{2}$ & $1.21(0.96-1.53)$ & 0.114 & $1.47(1.01-2.12)$ & 0.042 \\
\hline$\triangle \mathrm{hSBP}$ & $0.95(0.88-1.02)$ & 0.132 & $0.94(0.87-1.02)$ & 0.150 \\
\hline$\triangle \mathrm{hDBP}$ & $0.96(0.90-1.02)$ & 0.197 & $0.95(0.87-1.04)$ & 0.302 \\
\hline \multicolumn{5}{|l|}{ Men } \\
\hline $\mathrm{HR}$ at rest & $1.02(0.98-1.07)$ & 0.310 & $1.02(0.97-1.07)$ & 0.362 \\
\hline $\mathrm{SpO}_{2}$ at rest & $1.45(0.95-2.20)$ & 0.083 & $1.47(0.95-2.28)$ & 0.086 \\
\hline $\mathrm{SBP}$ at rest & $1.01(0.96-1.05)$ & 0.795 & $1.00(0.96-1.05)$ & 0.924 \\
\hline DBP at rest & $1.02(0.97-1.06)$ & 0.484 & $1.01(0.97-1.06)$ & 0.593 \\
\hline$\Delta \mathrm{eHR}$ & $0.96(0.91-1.01)$ & 0.090 & $0.96(0.91-1.01)$ & 0.100 \\
\hline$\Delta \mathrm{eSpO}{ }_{2}$ & $0.57(0.40-0.80)$ & 0.001 & $0.56(0.39-0.79)$ & 0.001 \\
\hline$\triangle \mathrm{eSBP}$ & $1.02(0.97-1.06)$ & 0.477 & $1.02(0.97-1.06)$ & 0.444 \\
\hline$\triangle \mathrm{eDBP}$ & $1.01(0.97-1.04)$ & 0.748 & $1.01(0.97-1.04)$ & 0.792 \\
\hline$\Delta h H R$ & $1.00(0.96-1.04)$ & 0.969 & $1.01(0.97-1.05)$ & 0.822 \\
\hline$\Delta \mathrm{hSpO}_{2}$ & $0.97(0.85-1.10)$ & 0.617 & $0.98(0.86-1.13)$ & 0.785 \\
\hline$\triangle \mathrm{hSBP}$ & $0.98(0.94-1.01)$ & 0.172 & $0.97(0.94-1.01)$ & 0.123 \\
\hline$\triangle \mathrm{hDBP}$ & $0.98(0.94-1.02)$ & 0.260 & $0.98(0.94-1.02)$ & 0.290 \\
\hline
\end{tabular}

Adjusted analysis Adjusted for age, height, weight, and smoking status. AMS Acute mountain sickness, $H R$ Heart rate, $\mathrm{SpO}_{2}$ Pulse oxygen saturation, $\mathrm{SBP}$ Systolic blood pressure, DBP Diastolic blood pressure, $\triangle e$ Change after exercise testing, $\Delta h$ Change after arriving at $4100 \mathrm{~m}$

sea level to Lhasa by aircraft, AMS incidence has been reported to be $57 \%$ [23]. The rate of AMS at $47.5 \%$ in the current study is generally consistent with these previous reports. The discrepancy among the studies may reflect differences in a variety of factors, including field conditions, the speed of ascent, arrival altitude, ethnicity of the enrolled study subjects, as well as timing of AMS assessment after the ascent.

\section{Sex differences}

Sex differences in AMS has been previously report, but with inconsistent conclusions. A meta-analysis supported higher susceptibility in women [24]. In the current study, we confirmed higher rate of AMS in women. Notably, $75.0 \%$ of the women in the current study developed AMS upon ascent to $4100 \mathrm{~m}$. This rate is similar to a study by Boos CJ in which $69.2 \%$ of women developed AMS [25]. The Boos study also suggested that anxiety at low altitude is an independent predictor of AMS upon ascent, and women tend to have higher level of anxiety. The fact that anxiety levels are higher in younger adults and women may partly explain the difference in AMS susceptibility between women and men [26]. However, Pesce et al. failed to show a difference in the rate of AMS between men and women [27]. Wagner et al. [15] even found higher risk of AMS in men. These inconsistent findings may be attributed to the ethnic and age differences, different levels of anxiety, history of high altitude exposure, experience with hiking, and prophylactic use of pharmacological agents. In addition, Gatterer et al. [28] found that resting cortisol levels at sea level are associated with fluid balance and AMS risk after ascent, suggesting the involvement of autonomic nervous and endocrine system.

Higher incidence of AMS in women may be explained by the effects of hormones. First, testosterone possess potent erythropoiesis action [29]. High serum testosterone and hemoglobin levels are conducive to improvements in oxygen transport, normal cellular function and thus lower susceptibility to AMS. Second, 17 betaestradiol could reduce the operating point for osmoregulation of arginine vasopressin and contribute to fluid retention [30]. Seventeen beta-estradiol could also upregulate the expression of vascular endothelial growth factor (VEGF), which in turn promotes endothelial cellular proliferation, angiogenesis and vascular permeability [31]. Fluid retention and increased permeability of the vascular endothelium compromise the blood-brain barrier and promote brain tissue swelling and intracranial hypertension [32].

\section{Predictive value of exercise testing}

Under hypoxia, the sympathetic system is activated to ensure a sufficient oxygen supply. Heart rate variability (HRV) is a common indicator that reflects the balance of cardiac autonomic nervous function between the sympathetic system and the parasympathetic system. HRV has been found to be associated with AMS risk; however, the assessment of HRV requires 12-lead electrocardiogram; more importantly, the prediction value was limited [33]. A more convenient indicator is needed for the general population under field conditions. A previous study suggested that decreased $\mathrm{SpO}_{2}$ at rest increases the likelihood of AMS upon ascent to high altitude [34]. Fluid accumulation in the pulmonary vasculature and/or inflammatory reactions in the peripheral airways may reduce pulmonary gas exchange under hypoxic conditions. This may further decrease $\mathrm{SaO}_{2}$ and cause hypoxia-induced illness. Exercise testing under hypobaric conditions in laboratory could identify subjects who will develop severe HAI upon ascent 


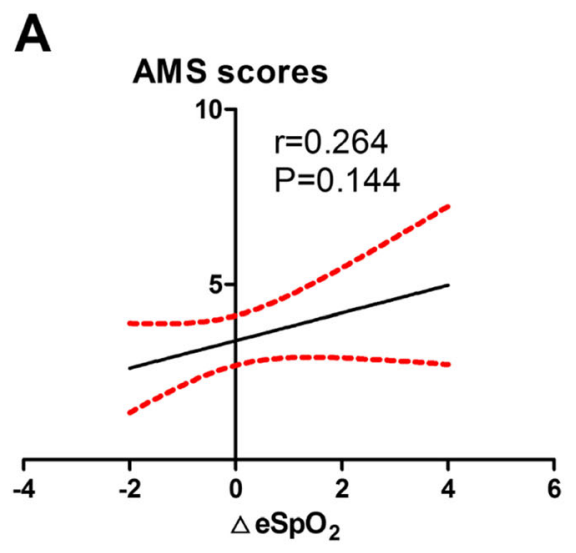

Women
B

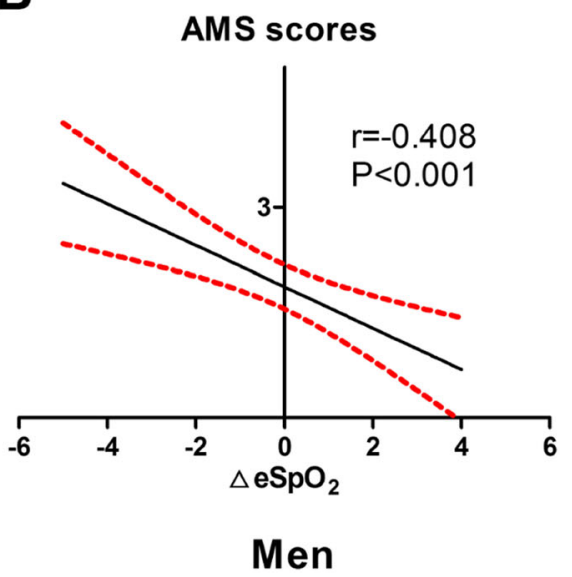

Fig. 2 The linear relationship between AMS scores and $\Delta \mathrm{eSpO}_{2}$ at sea level. The linear relationship between $\mathrm{AMS}$ scores and $\Delta \mathrm{eSpO}$ in a): Women, b): Men. AMS. Acute mountain sickness; $\mathrm{SpO}_{2}$. Pulse oxygen saturation; $\Delta \mathrm{e}$. Change in value after exercise testing

in some but not all studies $[35,36]$. Also, such method is apparently not suitable as a screening test to identify subjects susceptible for the less severe AMS in the general population [13].

In the current study, $\mathrm{SpO}_{2}$ change after arriving at $4100 \mathrm{~m}$ was positively correlated with AMS in women. In addition to the effects of hormones, the regulation of the respiratory system and changes in physiological parameters also play important roles in the development of AMS. Relatively smaller tidal volume and higher breathing frequency in women could conceivably lead to increased strain on respiratory muscles under hypoxia and exercise conditions. Women are also more susceptible to hypoxemia, which may explain why the higher incidence of AMS in women observed in the current study as well as in previous studies [37]. We also showed an association between $\mathrm{SpO}_{2}$ change after exercise testing at low altitude with AMS risk in the entire cohort, and more so in men. $\Delta \mathrm{eSpO}_{2}$ after exercise testing at low altitude was also positively correlated with AMS score in the men, suggesting that $\Delta \mathrm{eSpO}_{2}$ after mild exercise could be a useful tool to predict AMS. Subjects with higher maximal oxygen consumption $\left(\mathrm{VO}_{2 \max }\right)$ values perform better at endurance exercise. $\mathrm{VO}_{2 \max }$ has been shown to be strongly associated with red cell volume and hemoglobin concentration [38]. Higher $\mathrm{VO}_{2 \max }$, red cell volume and hemoglobin concentration as the result of testosterone stimulation may partly explain the low incidence of AMS in men. When subjects exercised at equal intensity, the oxygen consumption in men was more remarkable, and exercise-induced desaturation could predict AMS risk. However, this did not translate into an increased incidence of AMS in men.

Consistent with a meta-analysis study about smoking and AMS [39], we found a lower percentage of smokers in the AMS group. Smokers have higher basal carbon monoxide (CO) [40], which in turn decrease cerebral blood flow velocities, and thus decreased risk of high altitude headache and AMS [41]. CO could occupy the binding sites of hemoglobin and decrease the oxygen content in the circulating blood [42]. These mechanisms may explain why smokers are less susceptible to AMS in the current study. In a previous study by Wu et al. [43], smoking was also a protective factor against AMS during acute hypoxia exposure. Such a finding by no means advocate smoking, since smoking could impair long-term acclimatization in addition to causing a variety of serious health problems.

\section{Other factors related to AMS}

Age has been inversely associated with AMS in some [44], but not all studies [45]. Trekkers younger than 60 years are twice as likely to develop AMS [46], possibly due to less experience and more rapid ascent. The ratio of cranial cerebrospinal fluid to brain volume increases with age, and may serve as a compensatory adaptation to limit the effect of brain swelling and ultimately decreased susceptibility to AMS. Also, respiratory responses to hypoxia and blood oxygenation increase with age in men, and lung diffusion limitation was less prominent in older people [44]. These findings may help to explain the wide difference in exercise-induced desaturation under hypoxic conditions across age groups.

Ge et al. [47] found higher AMS score and lower $\mathrm{SaO}_{2}$ in obese subjects. Such a phenomenon may be partly related to greater $\mathrm{SpO}_{2}$ reduction during the night at high altitude. In the current study, BMI was lower in the AMS group. In addition to BMI, however, other factors (e.g., waist, body fat and body composition) may also affect the development of AMS. As a result, BMI should not be considered in isolation. For example, the female 
sex was strongly associated with increased AMS risk. Whether and how AMS susceptibility in women is connected to lower weight and BMI in women requires further studies.

\section{Limitations}

The present study does have limitations. First, participating subjects were mostly young despite of a wide range (19-59 years). Whether the findings could be extrapolated to older population remains unknown. Second, we used a single elevation and single ascending rate. The findings need to be validated in studies with different protocols. Third, the sample size of women was relatively small $(n=32)$. More importantly, men and women were not well matched by age and BMI. Lastly, the intensity of exercise was mild. $\mathrm{SpO}_{2}$ reduction after exercise testing therefore is relatively small. Exercise programs with higher intensity might be more sensitive to identify persons at risk to develop AMS.

\section{Conclusion}

AMS is common if the ascent to $4100 \mathrm{~m}$ is completed within 2 days. AMS is more common and severe in women than in men. $\mathrm{SpO}_{2}$ reduction at low altitude could be used to predict AMS upon ascent in men but not in women, indicating major sex differences.

\section{Abbreviations}

AMS: Acute mountain sickness; BMI: Body mass index; Cl: Confidence intervals; CO: Carbon monoxide; DBP: Diastolic blood pressure; HACE: Highaltitude cerebral edema; HAl: High-altitude illness; HIF: Hypoxia inducible factor; HR: Heart rate; OR: Odds ratio; $\mathrm{SaO}_{2}$ : Arterial oxygen saturation; SBP: Systolic blood pressure; $\mathrm{SpO}_{2}$ : Pulse oxygen saturation; $\mathrm{VO}_{2 \text { max }}$ : Maximal oxygen consumption; $\Delta \mathrm{e}$ : Change after the exercise testing at low altitude; $\Delta \mathrm{h}$ : Change after arriving at $4100 \mathrm{~m}$

\section{Acknowledgments}

The authors are grateful to all participants in this study for their support.

\section{Authors' contributions}

$\mathrm{LH}, \mathrm{CL}$ and JHZ conceived and designed the experiments. YS, YQY, FZYY, JBK, CYH, LPZ and CZ performed field experiments and collected data both at sea level and in Lhasa. YQY performed the statistical analyses, created the tables and figures, and wrote the results section. YS analyzed the data, interpreted the results and wrote the initial manuscript. $C L, J Y, J J, H T$, JY and $\mathrm{LH}$ critically reviewed and modified the manuscript. All authors approved the final manuscript.

\section{Funding}

This study was supported by grants from the Research Project of PLA (BLJ18J007), the National Natural Science Foundation of China (81730054) and the Ministry of Health of China (201002012).

\section{Availability of data and materials}

All data generated or analyzed during this study are included in this published article.

\section{Ethics approval and consent to participate}

All procedures in this study were approved by the Clinical Research Ethics Board of Army Medical University (identification code, 201907501; approved 15 July, 2019). All subjects were informed of the study purpose and procedure in detail and volunteered to participate in this study. Written informed consent was obtained from all subjects prior to the study.
Consent for publication

Not applicable.

\section{Competing interests}

The authors declare that they have no competing interests.

Received: 4 January 2020 Accepted: 20 October 2020

Published online: 05 November 2020

\section{References}

1. Roach RC, Hackett PH, Oelz O, Bärtsch P, Luks AM, Maclnnis MJ, et al. The 2018 Lake Louise Acute Mountain sickness score. High Alt Med Biol. 2018; 19(1):4-6.

2. Jin J. Acute mountain sickness. JAMA. 2017;318(18):1840.

3. Luks AM, Swenson ER, Bärtsch P. Acute high-altitude sickness. Eur Respir Rev. 2017;26(143):160096.

4. Basnyat B. Acute high-altitude illnesses. N Engl J Med. 2013;369(17):1666

5. Bärtsch P, Swenson ER. Clinical practice: acute high-altitude illnesses. N Engl J Med. 2013;368(24):2294-302.

6. Gonggalanzi, Labasangzhu, Nafstad P, Stigum H, Wu T, Haldorsen $\varnothing D$, et al. Acute mountain sickness among tourists visiting the high-altitude city of Lhasa at 3658 m above sea level: a cross-sectional study. Arch Public Health. 2016;74:23.

7. Meier D, Collet TH, Locatelli I, Cornuz J, Kayser B, Simel DL, et al. Does this patient have Acute Mountain sickness?: the rational clinical examination systematic review. JAMA. 2017;318(18):1810-9.

8. Richalet JP, Larmignat $P$, Poitrine $E$, Letournel $M$, Canouï-Poitrine $F$. Physiological risk factors for severe high-altitude illness: a prospective cohort study. Am J Respir Crit Care Med. 2012;185(2):192-8.

9. Sikri G, Srinivasa AB, Chawla A. Acute mountain sickness and obesity. Eur Rev Med Pharmacol Sci. 2015;19(21):4086.

10. McDevitt M, McIntosh SE, Rodway G, Peelay J, Adams DL, Kayser B. Risk determinants of acute mountain sickness in trekkers in the Nepali Himalaya: a 24-year follow-up. Wilderness Environ Med. 2014;25(2):152-9.

11. Santantonio M, Chapplain JM, Tattevin P, Leroy H, Mener E, Gangneux JP, et al. Prevalence of and risk factors for acute mountain sickness among a cohort of high-altitude travellers who received pre-travel counselling. Travel Med Infect Dis. 2014;12(5):534-40.

12. Headache Classification Subcommittee of the International Headache Society. The International Classification of Headache Disorders: 2nd edition. Cephalalgia. 2004;24(Suppl. 1):9-160.

13. Canouï-Poitrine F, Veerabudun $K$, Larmignat $P$, Letournel M, Bastuji-Garin S, Richalet JP. Risk prediction score for severe high altitude illness: a cohort study. PLoS One. 2014;9(7):e100642.

14. Norcliffe L, Rivera-Ch M, Claydon VE, Moore JP, Leon-Velarde F, Appenzeller $\mathrm{O}$, et al. Cerebrovascular responses to hypoxia and hypocapnia in highaltitude dwellers. J Physiol. 2005;566(Pt 1):287-94.

15. Wagner DR, D'Zatko K, Tatsugawa K, Murray K, Parker D, Streeper T, et al. Mt. Whitney: determinants of summit success and acute mountain sickness. Med Sci Sports Exerc. 2008:40(10):1820-7.

16. Parati G, Agostoni P, Basnyat B, Bilo G, Brugger H, Coca A, et al. Clinical recommendations for high altitude exposure of individuals with pre-existing cardiovascular conditions: A joint statement by the European Society of Cardiology, the Council on Hypertension of the European Society of Cardiology, the European Society of Hypertension, the International Society of Mountain Medicine, the Italian Society of Hypertension and the Italian Society of Mountain Medicine. Eur Heart J. 2018;39(17):1546-54.

17. Karinen HM, Peltonen JE, Kähönen M, Tikkanen HO. Prediction of acute mountain sickness by monitoring arterial oxygen saturation during ascent. High Altitude Med Biol. 2010;11(4):325-32.

18. Boos CJ, Woods DR, Varias A, Biscocho S, Heseltine P, Mellor AJ. High altitude and Acute Mountain sickness and changes in circulating Endothelin-1, Interleukin-6, and interleukin-17a. High Alt Med Biol. 2016; 17(1):25-31.

19. Leichtfried V, Basic D, Burtscher M, Gothe RM, Siebert U, Schobersberger W. Diagnosis and prediction of the occurrence of acute mountain sickness measuring oxygen saturation--independent of absolute altitude? Sleep Breath. 2016;20(1):435-42.

20. Boos CJ, Mellor A, O'Hara JP, Tsakirides C, Woods DR. The effects of sex on cardiopulmonary responses to acute Normobaric hypoxia. High Alt Med Biol. 2016;17(2):108-15 
21. Sheel AW, Richards JC, Foster GE, Guenette JA. Sex differences in respiratory exercise physiology. J Sports Med. 2004;34(9):567-79.

22. Pratali L, Allemann Y, Rimoldi SF, Faita F, Hutter D, Rexhaj E, et al. RV contractility and exercise-induced pulmonary hypertension in chronic mountain sickness: a stress echocardiographic and tissue Doppler imaging study. J Am Coll Cardiol Img. 2013;6(12):1287-97.

23. Ren Y, Fu Z, Shen W, Jiang P, He Y, Peng S, et al. Incidence of high altitude illnesses among unacclimatized persons who acutely ascended to Tibet. High Alt Med Biol. 2010;11(1):39-42.

24. Hou YP, Wu JL, Tan C, Chen Y, Guo R, Luo YJ. Sex-based differences in the prevalence of acute mountain sickness: a meta-analysis. Mil Med Res. 2019; 6(1):38.

25. Boos CJ, Bass M, O'Hara JP, Vincent E, Mellor A, Sevier L, et al. The relationship between anxiety and acute mountain sickness. PLoS One. 2018; 13(6):e0197147.

26. Remes $\mathrm{O}$, Brayne $\mathrm{C}$, van der Linde $\mathrm{R}$, Lafortune L. A systematic review of reviews on the prevalence of anxiety disorders in adult populations. Brain Behav. 2016;6(7):e00497.

27. Pesce C, Leal C, Pinto H, González G, Maggiorini M, Schneider M, et al. Determinants of acute mountain sickness and success on Mount Aconcagua (6962 m). High Alt Med Biol. 2005;6(2):158-66.

28. Gatterer H, Bernatzky G, Burtscher J, Rainer M, Kayser B, Burtscher M. Are pre-ascent low-altitude saliva cortisol levels related to the subsequent Acute Mountain sickness score? Observations from a field study. J High Alt Med Biol. 2019;20(4):337-43.

29. Ding XH, Wang Y, Cui B, Qin J, Zhang JH, Rao RS, et al. Acute Mountain Sickness Is Associated With a High Ratio of Endogenous Testosterone to Estradiol After High-Altitude Exposure at 3,700 m in Young Chinese Men. Front Physiol. 2018;9:1949.

30. Stachenfeld NS, Silva C, Keefe DL, Kokoszka CA, Nadel ER. Effects of oral contraceptives on body fluid regulation. J Appl Physiol. 1999;87(3):1016-25.

31. Zhu Y, Zhang Q, Zhang W, Li N, Dai Y, Tu J, et al. Protective effect of 17ßestradiol upon hippocampal spine density and cognitive function in an animal model of vascular dementia. J Scientific reports. 2017:7:42660.

32. Hackett PH, Roach RC. High-altitude illness. N Engl J Med. 2001;345(2):107-14.

33. Karinen HM, Uusitalo A, Vähä-Ypyä H, Kähönen M, Peltonen JE, Stein PK, et al. Heart rate variability changes at $2400 \mathrm{~m}$ altitude predicts acute mountain sickness on further ascent at 3000-4300 m altitudes. J Front Physiol. 2012;3:336.

34. Faulhaber M, Wille M, Gatterer H, Heinrich D, Burtscher M. Resting arterial oxygen saturation and breathing frequency as predictors for acute mountain sickness development: a prospective cohort study. Sleep Breath. 2014;18(3):669-74

35. Richalet JP, Canoui-Poitrine F. Pro: hypoxic cardiopulmonary exercise testing identifies subjects at risk for severe high altitude illnesses. High Alt Med Biol. 2014;15(3):315-7.

36. Bärtsch P. Con: hypoxic cardiopulmonary exercise testing identifies subjects at risk for severe high altitude illnesses. High Alt Med Biol. 2014;15(3):318-20.

37. Dominelli PB, Molgat-Seon Y, Griesdale DEG, Peters CM, Blouin JS, Sekhon $M$, et al. Exercise-induced quadriceps muscle fatigue in men and women: effects of arterial oxygen content and respiratory muscle work. J Physiol. 2017;595(15):5227-44.

38. Schmidt W, Prommer N. Impact of alterations in total hemoglobin mass on $\mathrm{VO}_{2}$ max. J Exerc Sport Sci Rev. 2010;38(2):68-75.

39. Xu C, Lu HX, Wang YX, Chen Y, Yang SH, Luo YJ. Association between smoking and the risk of acute mountain sickness: a meta-analysis of observational studies. Mil Med Res. 2016:3:37.

40. Brenckmann V, Ventrillard I, Romanini D, Jaulin $K$, Calabrèse P, Briot R. High inhaled oxygen concentration quadruples exhaled $\mathrm{CO}$ in healthy volunteers monitored by a highly sensitive laser spectrometer. Sci Rep. 2019;9(1):12259.

41. Song P, Zhang JH, Qin J, Gap XB, Yu J, Tang XG, et al. Smoking is associated with the incidence of AMS: a large-sample cohort study. Mil Med Res. 2014;1:16.

42. Moore-Gillon J. Smoking-a major cause of polycythemia. J R Soc Med. 1988;81(7):431.

43. Wu TY, Ding SQ, Liu JL, Jia JH, Chai ZC, Dai RC, et al. Smoking, acute mountain sickness and altitude acclimatisation: a cohort study. Thorax. 2012;67(10):914-9.

44. Richalet JP, Lhuissier FJ. Aging, tolerance to high altitude, and cardiorespiratory response to hypoxia. High Alt Med Biol. 2015;16(2):117-24.

45. Tang XG, Zhang JH, Qin J, Gao XB, Li QN, Yu J, et al. Age as a risk factor for acute mountain sickness upon rapid ascent to $3,700 \mathrm{~m}$ among young adult Chinese men. Clin Interv Aging. 2014;9:1287-94.
46. Croughs M, Van Gompel A, Van den Ende J. Acute mountain sickness in travelers who consulted a pre-travel clinic. J Travel Med. 2011;18(5):337-43.

47. Hu CJ, Wang LY, Chodosh LA, Keith B, Simon MC. Differential roles of hypoxia-inducible factor 1alpha (HIF-1alpha) and HIF-2alpha in hypoxic gene regulation. Mol Cell Biol. 2003;23(24):9361-74.
Ready to submit your research? Choose BMC and benefit from:

- fast, convenient online submission

- thorough peer review by experienced researchers in your field

- rapid publication on acceptance

- support for research data, including large and complex data types

- gold Open Access which fosters wider collaboration and increased citations

- maximum visibility for your research: over $100 \mathrm{M}$ website views per year

At BMC, research is always in progress.

Learn more biomedcentral.com/submissions 